\title{
Perceived Discrimination in Clinical Care in a Nationally Representative Sample of HIV-Infected Adults Receiving Health Care
}

\author{
Mark A. Schuster, MD, PhD, 1,2,3 Rebecca Collins, PhD, ${ }^{7}$ William E. Cunningham, MD, MPH, ,4 \\ Sally C. Morton, PhD, ${ }^{1}$ Sally Zierler, PhD, ${ }^{5}$ Myra Wong, BA, ${ }^{2}$ Wenli Tu, MS,
} David E. Kanouse, $P h D^{7}$

'RAND, Santa Monica, Calif, USA; ²Department of Pediatrics, David Geffen School of Medicine, University of California, Los Angeles, Calif, USA; ${ }^{3}$ Department of Health Services, School of Public Health, University of California, Los Angeles, Calif, USA; ${ }^{4}$ Department of Medicine, David Geffen School of Medicine, University of California, Los Angeles, Calif, USA; ${ }^{5}$ Department of Community Health, Brown University, Providence, RI, USA.

BACKGROUND: Perceived discrimination in clinical settings could discourage HIV-infected people from seeking health care, adhering to treatment regimens, or returning for follow-up.

OBJECTIVES: This study aims to determine whether HIV-infected people perceive that physicians and other health care providers have discriminated against them.

DESIGN, PARTICIPANTS: Cross-sectional data (1996 to 1997) from the HIV Cost and Services Utilization Study (HCSUS), which conducted in-person interviews with a nationally representative probability sample of 2,466 HIV-infected adults receiving health care within the contiguous U.S.

MEASUREMENTS: Reports of whether health care providers have been uncomfortable with the respondent, treated the respondent as an inferior, preferred to avoid the respondent, or refused the respondent service. Questions also covered the types of providers who engaged in these behaviors.

RESULTS: Twenty-six percent of HIV-infected adults receiving health care reported experiencing at least 1 of 4 types of perceived discrimination by a health care provider since becoming infected with HIV, including $8 \%$ who had been refused service. White respondents $(32 \%)$ were more likely than others (27\%) and Latinos (21\%) and nearly twice as likely as African Americans (17\%) to report perceived discrimination $(P<.001)$. Respondents whose first positive HIV test was longer ago were also more likely to report discrimination $(P<.001)$. Respondents who reported discrimination attributed it to physicians (54\%), nurses and other clinical staff (39\%), dentists (32\%), hospital staff (31\%), and case managers or social workers $(8 \%)$.

CONCLUSIONS: Many HIV-infected adults believe that their clinicians have discriminated against them. Clinicians should make efforts to address circumstances that lead patients to perceive discrimination, whether real or imagined.

KEY WORDS: discrimination; HIV care; prejudice. DOI: $10.1111 /$ j.1525-1497.2005.0169.x J GEN INTERN MED 2005; 20:807-813.

$\mathrm{D}$ iscrimination in the health care system against HIV-infected people has been observed since the epidemic was recognized. ${ }^{1-8}$ Some discriminatory acts are overt, such as refusing to provide treatment ${ }^{6,8}$ or making derogatory statements. ${ }^{9-11}$ Other forms are more subtle, such as providing less emotional support or less thorough care than usual. ${ }^{1,12,13}$ Studies show that doctors and other clinicians sometimes har-

The authors have no conflicts of interest to report.

Address correspondence and reprint requests to Dr. Schuster: RAND, 1776 Main St., Santa Monica, CA 90407-2138 (e-mail: schuster@ rand.org). bor prejudiced beliefs that could lead to discrimination, ${ }^{7,14-23}$ and other studies document patient reports that clinicians have discriminated against them..$^{5,8,24-28}$ It is illegal for clinicians, clinics, and hospitals to discriminate on the basis of HIV status. ${ }^{28,29}$

Discrimination against HIV-infected people may be more complex than against people with other diseases. HIV predominantly affects groups who are stigmatized in the absence of infection (e.g., gay men, injection drug users (IDU)), ${ }^{8,15,16,30-33}$ and it disproportionately affects African Americans and Latinos, ${ }^{34,35}$ who experience racial/ethnic discrimination independent of HIV. ${ }^{36-39}$ Therefore, HIV-infected people may experience discrimination because of their infection, another characteristic, or both.

Discrimination based on race/ethnicity, gender, and socioeconomic status has been reported in health care $\mathrm{c}^{36,40-44}$ and can affect patients' health. For example, patients who report experiencing racial/ethnic discrimination have worse health outcomes. ${ }^{38,43,44}$ Fear of discrimination keeps some HIV-infected patients from disclosing their infection to clinicians, ${ }^{45,46}$ which could compromise receipt of appropriate care. Feeling that one's clinician has negative attitudes toward one's group or experiencing overt discrimination may have an adverse effect on psychological health. ${ }^{4-51}$ Such effects depend on patients' perceptions of discrimination, and not necessarily on clinicians' objective behavior, indicating the importance of gaining a better understanding of discrimination from the perspective of HIV-infected individuals.

We sought to determine how many HIV-infected people felt that they experienced discrimination in seeking health care. We examined the prevalence and characteristics of people who report perceived discrimination and the types of providers these individuals believe discriminated against them. We also assessed whether perceived discrimination is related to self-reported access to care, quality ratings of medical and hospital care, and trust in doctors or clinics. We addressed these issues with data from a nationally representative sample of HIV-infected adults receiving health care.

\section{METHODS}

\section{Study Design}

The HIV Cost and Services Utilization Study (HCSUS) used multistage national probability sampling to select a random

Received for publication July 8, 2004

and in revised form March 31, 2005

Accepted for publication April 4, 2005 
sample of adults with known HIV infection and a health care visit at a nonmilitary, -prison, or -emergency facility during a 2-month population-definition period in early $1996 .{ }^{52-54}$ First, we sampled the 8 metropolitan statistical areas (MSAs) with the largest AIDS caseloads with certainty plus an additional 20 MSAs and 24 rural county clusters. Next, we sampled 58 urban and 28 rural "known providers" from lists of all providers known by local informants to provide HIV care. To ensure representation of all HIV providers, we sampled 87 urban and 23 rural "other providers" who affirmed caring for HIV-infected patients in a screening survey of about 4,000 physicians randomly selected from the American Medical Association master file. Finally, we sampled patients from anonymous lists of all eligible patients who visited participating providers during the population-definition period. We removed duplicate entries across lists where possible. Women and staff-model HMO patients were oversampled. Trained interviewers conducted inperson computer-assisted personal interviews. ${ }^{55}$

This article covers data from wave 2 (December 1996 to July 1997); some independent variables come from wave 1 (January 1996 to April 1997). Wave 1 included 2,864 full interviews; the coverage rate (the population directly represented divided by the population that would have been represented with complete participation) was $68 \%$ for full interviews. Wave 2 included 2,466 respondents ( $86 \%$ of the original cohort). Between waves, 238 people died and 359 were not located or were unwilling to participate. RAND's Institutional Review Board and local boards approved the study.

\section{Perceived Discrimination}

The main outcome measures were 4 yes/no questions each beginning with, "Since you have had HIV, has any health care provider ..." followed by, "been uncomfortable with you?," "treated you as an inferior?," "preferred to avoid you?," and "refused you service?" They were derived from previous studies. ${ }^{56,57}$

These items refer to experiences that could lead patients to perceive forms of discrimination ranging from a demonstration of mildly prejudiced attitudes to blatant mistreatment. ${ }^{58}$ For most analyses, we use a variable indicating whether the respondent reported at least 1 of the 4 experiences. We repeat some analyses with just the variable "refusal of care" because it is typically the most overt of the 4 . For the 23 respondents who were missing answers to some of these items (no respondent skipped all 4 items), we coded missing answers as "no." A sensitivity analysis showed that this approach did not have a substantial effect on the findings.

Respondents who answered yes to any question were asked, "Which of these providers has been uncomfortable with you? Treated you as an inferior? Preferred to avoid you? Refused you service?" and respondents were asked to reply yes or no for each of the following health care providers: a medical doctor or physician, a dentist, a nurse or other clinical staff, hospital staff, and case manager or social worker. If a respondent did not answer yes to any of the options, the response was coded as "someone else."

\section{Additional Outcomes}

We used a 6 -item access to care measure $(\alpha=0.74)$ derived from the HIV Outcomes Study and covering affordability, avail- ability, convenience, and specialist accessibility. ${ }^{59,60}$ We converted a 5-point Likert scale ("strongly agree" to "strongly disagree") to a 0 to 100 scale $(0,25,50,75,100)$. The mean of the 6 items provided a continuous measure.

We measured perceived quality of medical care with, "Overall, how would you rate the quality of the medical care you received in the past 6 months?" Respondents hospitalized overnight during the past 6 months were asked about perceived quality of hospital care: "Overall, how would you rate the care you received at the hospital?" Answer options for both questions were "poor," "fair," "good," "very good," or "excellent." Both categorical variables were adapted from prior studies. ${ }^{61,62}$

An adapted 2-item scale measured trust $(\alpha=0.87)^{63}$ : "How much do you trust your doctor or clinic to offer you high quality medical care?" and "How much do you trust your doctor or clinic to put your health above all other concerns?" This continuous measure was the mean of the 2 items after responses ("not at all," "a little," "somewhat," "mostly") were converted to 0 to 100 , similar to the conversion for access.

\section{Independent Variables}

Independent variables were chosen based on prior research and clinical reasoning. They included the following: (wave 1) gender, age, race/ethnicity, region of the country, MSA size, exposure/risk group, education, annual household income, date of first HIV-positive test, (wave 2) health insurance, and CD4 count. Baseline provider characteristics included HIV practice size, facility type, and facility teaching status.

Exposure/risk groups are ordered and mutually exclusive; respondents who fit more than 1 category appear in the category that comes first: men who had sex with men and were IDU (MM/IDU), MM, IDU, heterosexual, other.

Participants reported lowest ever CD4 count (if they did not know their exact count, we asked whether it was $>500$, 200 to 499,50 to 199 , or $<50 / \mathrm{mm}^{3}$ ). High agreement levels have been found between self-report and medical record CD4 counts in hospitalized patients. ${ }^{64}$

We inputed missing values ( $<5 \%$ for any variable) for independent variables (except insurance) using a standard "hotdeck" strategy. ${ }^{65,66}$ Twenty-one respondents missing "insurance" were omitted from relevant analyses.

\section{Analysis}

We examined bivariate relationships between each independent variable and all multivariate model outcomes. We included in Table 1 and in the models only variables that were significant at $P<.20$ for at least 1 outcome so that all models contain the same variables. Independent variables in Table 2 were used for additional regressions not shown in the tables but reported in the results.

We constructed analytic weights to adjust the sample to represent the reference population surviving until wave 2 (i.e., weights adjusted for sampling and attrition but not mortality). To adjust standard errors and statistical tests for differential weighting and complex sample design, we used linearization methods (SUDAAN, Research Triangle Park, NC, USA; Stata, College Station, TX, USA). ${ }^{66,67}$

We report unadjusted weighted proportions of dichotomous outcomes (e.g., discrimination) by independent variables (e.g., age) with $\chi^{2}$ tests of association. We report adjusted odds 
ratios from multivariate logistic regression models that incorporate the weights.

For the additional outcome measures, we fit linear regression models for the 2 continuous variables, and ordinal logistic regression models for the 2 categorical variables.

\section{RESULTS}

\section{Sample Characteristics}

Characteristics include male (77\%), African American (33\%), Latino (15\%), other (3\%), white (49\%); completed high school (75\%); 18 to 34 years old (34\%), 35 to 49 years old (55\%), 50 years, or over (11\%) (Table 1).

\section{Perceptions of Discrimination}

Twenty-six percent of U.S. adults receiving care for HIV reported at least 1 of 4 types of perceived discrimination in clinical settings after becoming infected with HIV. Specifically,

Table 1. Sample Characteristics

\begin{tabular}{|c|c|}
\hline Characteristics* & $\%$ \\
\hline \multicolumn{2}{|l|}{ Gender } \\
\hline Male $(n=169,800)$ & 77 \\
\hline Female $(n=49,800)$ & 23 \\
\hline \multicolumn{2}{|l|}{ Age (years) } \\
\hline 18 to $34(n=73,800)$ & 34 \\
\hline 35 to $49(n=121,400)$ & 55 \\
\hline $50+(n=24,400)$ & 11 \\
\hline \multicolumn{2}{|l|}{ Race/ethnicity } \\
\hline African American $(n=71,600)$ & 33 \\
\hline Latino $(n=32,600)$ & 15 \\
\hline Other $(n=7,200)$ & 3 \\
\hline White $(n=108,300)$ & 49 \\
\hline \multicolumn{2}{|l|}{ Exposure/risk group ${ }^{\dagger}$} \\
\hline MM/IDU $(n=17,800)$ & 8 \\
\hline $\operatorname{MM}(n=106,400)$ & 48 \\
\hline IDU $(n=35,800)$ & 16 \\
\hline Heterosexual $(n=41,100)$ & 19 \\
\hline Other $(n=18,500)$ & 8 \\
\hline \multicolumn{2}{|l|}{ Education } \\
\hline Less than high school $(n=54,400)$ & 25 \\
\hline High school degree or greater $(n=165,200)$ & 75 \\
\hline \multicolumn{2}{|l|}{ Insurance } \\
\hline No insurance $(n=38,500)$ & 18 \\
\hline Medicaid $(n=62,400)$ & 28 \\
\hline Private/HMO $(n=34,600)$ & 16 \\
\hline Private $(n=34,300)$ & 16 \\
\hline Medicare $(n=48,200)$ & 22 \\
\hline \multicolumn{2}{|l|}{$\mathrm{CD}$ count $^{\ddagger}$} \\
\hline 0 to $49(n=51,600)$ & 24 \\
\hline 50 to $199(n=67,900)$ & 31 \\
\hline 200 to $499(n=82,400)$ & 38 \\
\hline$\geq 500(n=17,800)$ & 8 \\
\hline \multicolumn{2}{|l|}{ Date of first HIV-positive test } \\
\hline Prior to $1986(n=17,900)$ & 8 \\
\hline 1986 to $1989(n=52,700)$ & 24 \\
\hline 1990 to $1993(n=84,200)$ & 39 \\
\hline 1994 to $1996(n=63,300)$ & 29 \\
\hline
\end{tabular}

${ }^{*}$ Unweighted $\mathrm{n}$ is 2,466; weighted $\mathrm{n}$ is 219,700 .

${ }^{\dagger} M M / I D U$, men who had sex with men and were injection drug users; $M M$, men who had sex with men; IDU, injection drug users. The list is hierarchical, so a respondent who fits in more than 1 category is placed in the highest of those categories.

${ }^{\ddagger}$ Participants were asked to report their lowest ever CD4 count; if they did not know their exact count, they were asked whether their lowest count was > 500, 200 to 499,50 to 199 , or $<50 / \mathrm{mm}^{3}$. they reported that a health care provider had been uncomfortable with them $(20 \%)$, treated them as an inferior (17\%), preferred to avoid them (18\%), or refused them service $(8 \%)$.

Some groups were more likely than others to report perceived discrimination. For example, white respondents (32\%) were more likely than others $(27 \%)$ and Latinos $(21 \%)$ and nearly twice as likely as African Americans (17\%) to report discrimination $(P<.001)$ (Table 2). Respondents who had completed high school (27\%) were more likely than those

Table 2. Percentage of Adults Receiving Health Care for HIV Who Perceived Discrimination and ORs from a Multivariate Logistic Regression Predicting Any Perceived Discrimination

\begin{tabular}{|c|c|c|}
\hline Characteristics* & $\% \ddagger$ & Adjusted OR $(95 \% \mathrm{Cl})^{\dagger \S}$ \\
\hline Gender & $P=.11$ & $P=.39$ \\
\hline Male & 26 & 1.0 \\
\hline Female & 22 & $1.16(0.82,1.67)$ \\
\hline Age (years) & $P=.11$ & $P=.12$ \\
\hline 18 to 34 & 26 & 1.0 \\
\hline 35 to 49 & 26 & $0.88(0.71,1.09)$ \\
\hline $50+$ & 20 & $0.72(0.52,1.01)$ \\
\hline Race/ethnicity & $P<.001$ & $P<.001$ \\
\hline African American & 17 & $0.45(0.35,0.58)$ \\
\hline Latino & 21 & $0.62(0.43,0.89)$ \\
\hline Other & 27 & $0.75(0.42,1.35)$ \\
\hline White & 32 & 1.0 \\
\hline Exposure/risk group ${ }^{\|}$ & $P=.002$ & $P=.53$ \\
\hline MM/IDU & 31 & $1.11(0.77,1.58)$ \\
\hline MM & 28 & 1.0 \\
\hline IDU & 24 & $1.05(0.79,1.39)$ \\
\hline Heterosexual & 20 & $0.97(0.67,1.40)$ \\
\hline Other & 17 & $0.70(0.45,1.08)$ \\
\hline Education & $P<.001$ & $P=.01$ \\
\hline Less than high school & 19 & 1.0 \\
\hline High school degree or greater & 27 & $1.45(1.09,1.91)$ \\
\hline Insurance & $P=.001$ & $P=.008$ \\
\hline No insurance & 18 & $1.09(0.78,1.52)$ \\
\hline Medicaid & 25 & $1.37(0.82,2.31)$ \\
\hline Private/HMO & 26 & $1.07(0.68,1.66)$ \\
\hline Private & 25 & 1.0 \\
\hline Medicare & 31 & $1.57(1.18,2.10)$ \\
\hline CD4 count & $P=.04$ & $P=.08$ \\
\hline 0 to 49 & 27 & $0.92(0.61,1.40)$ \\
\hline 50 to 199 & 28 & $0.96(0.54,1.70)$ \\
\hline 200 to 499 & 21 & $0.73(0.43,1.22)$ \\
\hline$\geq 500$ & 25 & 1.0 \\
\hline Date of first HIV-positive test ${ }^{\#}$ & $P<.001$ & $0.95(0.93,0.98) P=.001$ \\
\hline Prior to 1986 & 34 & \\
\hline 1986 to 1989 & 31 & \\
\hline 1990 to 1993 & 24 & \\
\hline 1994 to 1996 & 20 & \\
\hline
\end{tabular}

${ }^{*}$ Unweighted total $\mathrm{n}=2,417$; weighted total $\mathrm{n}=215,100$.

'ORs are adjusted for all variables in the table. For ease of interpretation, the ORs correspond to an increase of 10 units obtained by multiplying the original logistic regression coefficient (corresponding to an increase of one unit) by 10 and then exponentiating.

${ }^{\ddagger} \mathrm{P}$ values come from $a \chi^{2}$ test for the cross tabulations.

${ }^{\S} \mathrm{P}$ values come from an $\mathrm{F}$ test.

"MM/IDU, men who had sex with men and were injection drug users; $M M$, men who had sex with men; IDU, injection drug users. The list is hierarchical, so a respondent who fits in more than one category is placed in the highest of those categories.

"Participants were asked to report their lowest ever CD4 count; if they did not know their exact count, they were asked whether their lowest count was $>500,200$ to 499,50 to 199 , or $<50 / \mathrm{mm}^{3}$.

${ }^{\#}$ Date of first HIV+ test is a continuous variable and is entered as a continuous variable in the regression; it is presented as a categorical variable for the bivariate analysis for ease of interpretation.

$\mathrm{OR}$, odds ratio; $\mathrm{CI}$, confidence interval. 
Table 3. Reported Access to Care, Quality Ratings of Health Care Delivery, and Trust in Doctors or Clinics Among HIV-Infected People Who Did and Did Not Report Perceived Discrimination

\begin{tabular}{|c|c|c|c|c|c|c|c|c|c|c|c|c|}
\hline \multirow[t]{2}{*}{$\begin{array}{l}\text { Perceived } \\
\text { Discrimination }\end{array}$} & \multirow{2}{*}{$\begin{array}{c}\begin{array}{c}\text { Access to Care } \\
\text { (Current)* }(n=2,466)\end{array} \\
\text { Mean (SE) }\end{array}$} & \multicolumn{5}{|c|}{$\begin{array}{l}\text { Rating of Medical Care } \\
(6 \mathrm{mo})(n=2,449)(\%)\end{array}$} & \multicolumn{5}{|c|}{$\begin{array}{l}\text { Rating of Hospital Care } \\
(6 \mathrm{mo})(n=494)(\%)\end{array}$} & \multirow{2}{*}{$\frac{\text { Trust (Current) }^{*}(n=2,461)}{\text { Mean (SE) }}$} \\
\hline & & Poor & Fair & Good & Very Good & Excellent & Poor & Fair & Good & Very Good & Excellent & \\
\hline Yes & 78.3 (1.3) & 5 & 11 & 18 & 28 & 38 & 13 & 24 & 21 & 21 & 21 & $80.9(1.4)$ \\
\hline No & $82.7(0.9)$ & 1 & 7 & 18 & 33 & 41 & 4 & 17 & 20 & 31 & 28 & $87.1(1.0)$ \\
\hline$P$ value & .001 & \multicolumn{5}{|c|}{$<.001$} & \multicolumn{5}{|c|}{.01} & $<.001$ \\
\hline
\end{tabular}

Note: Perceived discrimination includes a report of at least 1 of 4 types of perceived discrimination asked about in the survey.

*Answers cover a 0 to 100 scale.

who had not $(19 \%)(P<.001)$ to report discrimination. Those who had their first HIV-positive test longer ago were also more likely to report discrimination $(P<.001)$. In addition, there was significant variation by type of insurance, HIV-exposure/risk group, and CD4 count. In a multivariate logistic regression, race/ethnicity, education, insurance, and date of first HIVpositive test remained significant predictors. When the outcome variable was the measure of refused care, the pattern of relationships was the same, except that education was not significant (data not shown).

\section{Types of Health Care Providers}

When people reporting discrimination were asked which providers had discriminated against them, they identified physicians $(54 \%)$, dentists $(32 \%)$, nurses or other clinical staff (39\%), hospital staff $(31 \%)$, case managers or social workers $(8 \%)$, and someone else $(2 \%)$.

\section{Access, Ratings of Care, and Trust}

Reported access to care, quality ratings of medical care and hospital care, and trust in doctors or clinics were lower for people who reported perceived discrimination (Table 3). In multivariate analyses controlling for respondent characteristics, discrimination remained significantly associated with each of these health care measures $(P<.001)$ (data not shown). Refused care was significant in all bi- and multivariate analyses when substituted for discrimination.

\section{DISCUSSION}

In a nationally representative sample of HIV-infected adults receiving health care, $26 \%$ perceived at least 1 of 4 types of discrimination by a health care provider since becoming infected. Over half of those who reported discrimination attributed it to physicians, about two-fifths to nurses and other clinical staff, nearly one-third each to dentists and hospital staff, and less than 1 in 10 to case managers and social workers. Our study did not include people who received no health care, received it only in emergency wards, or did not disclose their infection to their current clinicians. Because past discrimination could be a reason people forgo care or do not disclose, our study may underestimate the prevalence of perceived discrimination among HIV-infected people.

Our discrimination data were collected as more effective treatments were becoming available, and most of the HCSUS sample was cared for by experts in HIV care who were generalists $(45 \%)$ or infectious disease specialists (46\%). ${ }^{68}$ However, the perceived discrimination may reflect experiences with cli- nicians seen years earlier, so it does not necessarily reflect care received around the time of data collection. Moreover, clinicians' reactions to HIV-infected people could have changed since data collection. Nevertheless, despite their age, these data come from the only nationally representative study of HIVinfected people in care, and indeed, one of the only nationally representative datasets covering discrimination related to any disease.

In bi- and multivariate analyses, education, race/ethnicity, insurance, and time of first HIV-positive testing were all significant predictors of reports of perceived discrimination. People with higher educational attainment were more likely to report discrimination, possibly because of a greater awareness of discrimination and how it manifests in daily life.

Among racial/ethnic groups, fewer African Americans and Latinos than whites reported perceived discrimination. This finding may seem counterintuitive, although a dental care study of HIV-infected people found a similar result. ${ }^{27}$ There are several possible explanations.

Some groups may underreport discrimination. Members of groups that frequently experience discrimination may minimize their perceptions to preserve their self-esteem and sense of control over their lives. Or, they may find it upsetting to acknowledge the experience, or entertain the possibility that poor treatment was deserved. ${ }^{36,69,70}$ Some may mistakenly attribute discrimination to other characteristics (e.g., race/ethnicity, sexual orientation) rather than HIV. Even people who acknowledge that their group faces discrimination may report little personal discrimination. ${ }^{71}$ It may be so prevalent for some that they take it for granted. For example, African Americans and Latinos may typically experience worse care ${ }^{38,72-76}$ and thus be unaware that better care exists. By contrast, some white gay men, especially those who did not disclose their orientation to clinicians prior to HIV diagnosis, may have previously received nondiscriminatory care, making changes after infection more apparent. In bivariate analyses, men who have sex with men (regardless of injection drug use) were more likely than other exposure/risk groups to report discrimination.

Of course, there may simply be less health discrimination against African Americans and Latinos than against other groups with HIV. Clinicians might feel more hostility to people who are generally similar to themselves except for characteristics that they view negatively, such as being gay or having HIV. This phenomenon is called the "black sheep" effect. ${ }^{77,78}$ To maintain a belief in justice, people may blame other people, especially those with attributes similar to themselves, ${ }^{69}$ for the negative life events these other people experience. ${ }^{79}$ Although we do not know the characteristics of clinicians who were perceived to discriminate, some white clinicians may have a 
stronger negative reaction to treating HIV-infected patients who are racially/ethnically similar to themselves-and often gay-than patients who are racially/ethnically dissimilar.

Alternatively, African Americans and Latinos may go to facilities with less discrimination. Clinicians who work in clinics predominantly serving low-income African Americans may, through self-selection or socialization, be less likely to discriminate against HIV-infected people than clinicians working in hospitals with predominantly white or affluent patients. An analogous finding was reported in a study that showed that African Americans and people from poor neighborhoods tend to go to higher-quality health care institutions (i.e., urban teaching hospitals) than whites and people from nonpoor neighborhoods; consequently, although they receive worse care than others within an individual institution, as a group, they receive the same overall quality. ${ }^{80}$

Perceived discrimination was less prevalent for people diagnosed more recently. We do not know whether this finding is because of a shorter opportunity to experience discrimination, a change in the type of patients receiving care, or a shift in how clinicians react to HIV. Although it is encouraging that more recent cohorts may be experiencing less discrimination, it is also notable that even among people most recently diagnosed, $20 \%$ reported discrimination since of contracting HIV, raising concern that the health care system may have been making insufficient progress in improving clinician attitudes, reducing discrimination, and helping patients feel comfortable. Studies from the early 1990s and before showed that clinicians had HIV knowledge deficits and prejudiced attitudes toward treating HIV-infected patients. ${ }^{14-17,21-23,81,82}$ There has been little subsequent research on this subject, leaving us without evidence as to whether clinicians' knowledge and attitudes have changed.

Perceived discrimination was associated with lower perceived access to care, quality ratings of medical and hospital care, and trust in doctors or clinics. Any individual predisposition to perceive (or not to perceive) discrimination might influence perceptions of care. Also, our care measures cover recent time periods; someone who experienced past discrimination might now receive unbiased care. Nonetheless, these findings suggest a need for more research addressing the relationship between discrimination and the care that people receive.

Some examples of reported discrimination could arise from misperception. A patient may assume that an abrupt physician is prejudiced when he/she is actually abrupt with everyone. Similarly, a physician who refers patients to physicians with greater HIV expertise could be perceived as refusing care. Regardless of whether perceived discrimination indicates real bias, the perception of bias is important and can have consequences that interfere with health and health-promoting behavior. Besides causing stress, perceived discrimination can undermine confidence in clinicians-patients lose out on the positive health influences of a good doctor-patient relationship. ${ }^{83}$ Patients who perceive discrimination may be discouraged from seeking care, adhering to treatment regimens, or returning for follow-up. ${ }^{84,85}$ Moreover, clinicians work in a service profession, so they should provide an environment that is in fact caring, welcoming, and supportive-and that is perceived to be.

Although we are unable to validate whether discrimination occurred, refusal of service is less likely to be misperceived. It is especially concerning when refusal is reported by a group for whom the legal system has often had to intervene to assure access to care. ${ }^{6,86,87}$ Refused services might be ones not covered by a health plan or not indicated, but given the context in which the question was asked, respondents likely perceived services to have been refused inappropriately-and perceptions may very well have been accurate. Legal cases and anecdotal reports indicate that refusals are a part of the HIV experience. ${ }^{6,86}$ Without comparison data, we cannot determine whether people without HIV infection experience similar levels of perceived discrimination.

Interventions may reduce discrimination. ${ }^{81}$ Educational programs and modeling of nondiscriminatory behavior can teach clinicians and students to provide unbiased care. ${ }^{88-90}$ It may be easier to reduce discriminatory behavior than prejudiced attitudes ${ }^{77}$ and to reduce overt acts, such as refusing to provide care, than to change subtle behaviors, such as those that convey discomfort with HIV-infected patients. Research is needed to improve our understanding of how clinicians' behaviors can negatively affect patients' experiences, and effective strategies must be developed to reduce actual and perceived discrimination in health care.

This work was supported in part by the Agency for Health Care Policy and Research (U-01HS08578) and the Centers for Disease Control and Prevention (U48/CCU915773 and U48/ DP000056). This work does not necessarily represent the opinions of the funding organizations or of the institutions with which the authors are affiliated.

We are indebted to Laura M. Bogart, PhD, and Sarah Hunter, $P h D$, for recommending several references; to Steven LaFemina, BS, Janina L. Morrison, AB, and Katherine D. Vestal, $B A$, for research assistance; to Terry T. Nakazono, MA for programming; to Colleen M. Carey, BA, and Deborah G. Perlman, $B A$, for assistance with the manuscript; and to Martin F. Shapiro, $M D, P h D$, for comments on a draft of the manuscript. We also wish to thank the HCSUS Consortium for making the study possible and the study participants for sharing their time and stories.

\section{REFERENCES}

1. Gostin LO. The AIDS litigation project. A national review of court and human rights commission decisions, Part II: discrimination. JAMA. 1990;263:2086-93.

2. Herek GM. AIDS and stigma. Am Behav Sci. 1999;42:1106-16.

3. Gostin LO, Feldblum C, Webber DW. Disability discrimination in America: HIV/AIDS and other health conditions. JAMA. 1999;281:745-52.

4. Herek GM, Capitanio JP, Widaman KF. HIV-related stigma and knowledge in the United States: prevalence and trends, 1991-1999. Am J Public Health. 2002;92:371-7.

5. Annas GJ. Protecting patients from discrimination-the Americans with Disabilities Act and HIV infection. N Engl J Med. 1998;339:1255-9.

6. Shapiro J, Webber DW. Access to public services and accommodations. In: Webber DW, ed. AIDS and the Law. 3rd edn, Vol 4. New York, NY: John Wiley \& Sons; 1997:177-203.

7. Norton R, Schwartzbaum J, Wheat J. Language discrimination of general physicians: AIDS metaphors used in the AIDS crisis. Commun Res. 1990; 17:809-26.

8. Kass NE, Faden RR, Fox R, Dudley J. Homosexual and bisexual men's perceptions of discrimination in health services. Am J Public Health. 1992;82:1277-9.

9. Boston G. Diversity classes next for hospital. Atlanta J Constitution. October 2, 1999;3F.

10. Schwartz M. Gay men and the health care system. In: Peterson KJ, ed. Health Care for Lesbians and Gay Men: Confronting Homophobia and Heterosexism. New York, NY: Harrington Park Press/Haworth Press; 1996: 19-32.

11. Associated Press. Doctor defends refusal to treat AIDS patient. The Columbia Dispatch. June 2, 1994; 3C. 
12. Bunting SM. Sources of stigma associated with women with HIV. Adv Nurs Sci. 1996;19:64-73.

13. Levin BW, Driscoll JMJ, Fleischman AR. Treatment choice for infants in the neonatal intensive care unit at risk for AIDS. JAMA. 1991;265: 2976-81.

14. Kelly JA St., Lawrence JS, Smith SJ, Hood HV, Cook DJ. Stigmatization of AIDS patients by physicians. Am J Public Health. 1987;77: 789-91.

15. Kelly JA St., Lawrence JS, Smith SJ, Hood HV, Cook DJ. Medical students' attitudes toward AIDS and homosexual patients. J Med Educ. 1987;62:549-56.

16. Kelly JA St., Lawrence JS, Hood HV, Smith SJ, Cook DJ. Nurses' attitudes towards AIDS. J Contin Educ Nurs. 1988;19:78-83.

17. Forrester DA, Murphy PA. Nurses' attitudes toward patients with AIDS and AIDS-related risk factors. J Adv Nurs. 1992;17:1260-6.

18. Hayward RA, Shapiro MF. A national study of AIDS and residency training: experiences, concerns, and consequences. Ann Intern Med. 1991; 114:23-32.

19. Bennett ME, Weyant RJ, Wallisch JM, Green G. Dentists' attitudes toward the treatment of HIV-positive patients. J Am Dent Assoc. 1995; 126:509-14.

20. Feldmann TB, Bell RA, Stephenson JJ, Purifoy FE. Attitudes of medical school faculty and students toward acquired immunodeficiency syndrome. Acad Med. 1990;65:464-6.

21. Gerbert B, Sumser J, Chamberlin K, Maguire BT, Greenblatt RM, McMaster JR. Dental care experience of HIV-positive patients. J Am Dent Assoc. 1989;119:601-3.

22. Gemson DH, Colombotos J, Elinson J, Fordyce EJ, Hynes M, Stoneburner R. Acquired immunodeficiency syndrome prevention. Knowledge, attitudes, and practices of primary care physicians. Arch Intern Med. 1991;151:1102-8.

23. D'Augelli AR. AIDS fears and homophobia among rural nursing personnel. AIDS Educ Prev. 1989;1:277-84.

24. Sowell RL, Moneyham L, Aranda-Naranjo B. The care of women with AIDS: special needs and considerations. Nurs Clin North Am. 1999; 34:179-99.

25. Santiago LE. Oral testimonies: the other face of the HIV story. P R Health Sci J. 1998; 17:375-80.

26. Greene VA, Chu SY, Diaz T, Schable B. Oral health problems and use of dental services among HIV-infected adults. Supplement to HIV/AIDS surveillance project group. J Am Dent Assoc. 1997;128: 1417-22.

27. Burris S. Dental discrimination against the HIV-infected: empirical data, law and public policy. Yale J Regul. 1996;13:1-104.

28. Bragdon v Sidney Abbott: 118 S. Ct. 2196; 1998.

29. Americans with Disabilities Act of 1990

30. Burke BP, White JC. Wellbeing of gay, lesbian, and bisexual doctors. BMJ. 2001;322:422-5

31. Capitanio JP, Herek GM. AIDS-related stigma and attitudes toward injecting drug users among black and white Americans. Am Behav Sci. 1999;42:1148-61

32. Mays VM, Cochran SD. Mental health correlates of perceived discrimination among lesbian, gay and bisexual adults in the United States. Am J Public Health. 2001;91:1869-76.

33. Weiner B. AIDS from an attributional perspective. In: Reeder GD, ed. The Social Psychology of HIV Infection. Hillsdale, NJ: Lawrence Erlbaum Associates; 1993:287-302.

34. Centers for Disease Control and Prevention. HIV/AIDS-United States, 1981-2000. MMWR. 2001;50:429-56.

35. Centers for Disease Control and Prevention. HIV/AIDS Surveillance Report, 2003, Vol. 15. Atlanta, Ga: US Department of Health and Human Services, Centers for Disease Control and Prevention; 2004: Also available at: http://www.cdc.gov/hiv/stats/hasrlink.htm.

36. Krieger N, Sidney $\mathbf{s}$. Racial discrimination and blood pressure: the CARDIA study of young Black and White adults. Am J Public Health. 1996;86:1370-8

37. Ferguson JA, Weinberger M, Westmoreland GR, et al. Racial disparity in cardiac decision making: results from patient focus groups. Arch Intern Med. 1998;158:1450-3.

38. Smedley BD, Stitch AY, Nelson AR. Unequal Treatment: Confronting Racial and Ethnic Disparities in Health Care. Washington, DC: Institute of Medicine; 2002.

39. Kressin NR, Petersen LA. Racial differences in the use of invasive cardiovascular procedures: review of the literature and prescription for future research. Ann Intern Med. 2001;135:352-66.
40. Bird ST, Bogart LM. Perceived race-based and socioeconomic status (SES)-based discrimination in interactions with health care providers. Ethnic Dis. 2001;11:554-63.

41. Krieger N. Racial and gender discrimination: risk factors for high blood pressure? Soc Sci Med. 1990;30:1273-81.

42. Lillie-Blanton M, Brodie M, Rowland D, Altman D, McIntosh M. Race, ethnicity, and the health care system: public perceptions and experiences. Med Care Res Rev. 2000;1:218-35.

43. Ren XS, Amick BC, Williams DR. Racial/ethnic disparities in health: the interplay between discrimination and socioeconomic status. Ethnic Dis. 1999;9:151-65.

44. Bird ST, Bogart LM, Delahanty DL. Health-related correlates of perceived discrimination in HIV care. AIDS Patient Care STDS. 2004;18: 19-26.

45. Charbonneau A, Maheux B, Baeland F. Do people with HIV/AIDS disclose their HIV-positivity to dentists? AIDS Care. 1999;11:61-70.

46. McCarthy GM, Haji FS, Mackie ID. HIV-infected patients and dental care: nondisclosure of HIV status and rejection for treatment. Oral Surg Oral Med Oral Pathol Oral Radiol Endod. 1995;80:655-9.

47. Williams DR, Neighbors HW, Jackson JS. Racial/ethnic discrimination and health: findings from community studies. Am J Public Health. 2003;93:200-8.

48. Cohen MA. Biopsychosocial approach to the human immunodeficiency virus epidemic. A clinician's primer. Gen Hosp Psychiatr. 1990;12: 98-123.

49. Alonzo AA, Reynolds NR. Stigma, HIV and AIDS: an exploration and elaboration of a stigma trajectory. Soc Sci Med. 1995;41:303-15.

50. Kessler RC, Mickelson KD, Williams DR. The prevalence, distribution, and mental health correlates of perceived discrimination in the United States. J Health Soc Behav. 1999;40:208-30.

51. Sellers RM, Shelton JN. The role of racial identity in perceived racial discrimination. J Pers Soc Psychol. 2003;84:1079-92.

52. Bozzette SA, Berry SH, Duan N, et al. The care of HIV-infected adults in the United States HIV cost and services utilization study consortium. N Engl J Med. 1998;339:1897-904.

53. Frankel MR, Shapiro MF, Duan N, et al. National probability samples in studies of low-prevalence diseases. Part II: designing and implementing the HIV cost and services utilization study sample. Health Serv Res. 1999;34(5, Part I):969-93.

54. Lam NSN, Liu KB. Use of space-filling curves in generating a national rural sampling frame for HIV/AIDS research. Prof Geogr. 1996;48: 312-32.

55. Berry SH, Brown JA, Allen C, Keesey J, Allen J, Amidon T. HCSUS Baseline Patient Questionnaire Documentation. Santa Monica, Calif: RAND; 1998.

56. Jacoby A. Felt versus enacted stigma: a concept revisited. Soc Sci Med. 1994;38:269-74

57. Cunningham WE, Burton TM, Hawes-Dawson J, Kington RS, Hays RD. Use of relevancy ratings by target respondents to develop healthrelated quality of life measures: an example with African-American elderly. Qual Life Res. 2000;8:749-68.

58. Jones JM. Prejudice and Racism. Reading, Mass: Addison-Wesley Pub. Co.; 1972.

59. Cunningham WE, Hays RD, Williams KW, Beck KC, Dixon WJ, Shapiro MF. Access to medical care and health-related quality of life for lowincome persons with symptomatic human immunodeficiency virus. Med Care. 1995;33:739-54.

60. Cunningham WE, Andersen RM, Katz MH, et al. The impact of competing needs for basic subsistence on access to medical care for persons with HIV receiving care in the United States. Med Care. 1999;37: 1270-81

61. Cleary PD, Fahs MC, McMullen W, et al. Using patient reports to assess hospital treatment of persons with AIDS: a pilot study. AIDS Care. 1992;4:325-32.

62. Cleary PD, Edgman-Levitan S, McMullen W. A national survey of hospital patients: the relationship between reported problems with care and patient evaluations. Qual Rev Bull. 1993;18:53-9.

63. Kao AC, Green DC, Zaslavsky AM, Koplan JP, Cleary PD. The relationship between method of physician payment and patient trust. JAMA. 1998;280:1708-14.

64. Cunningham WE, Rana HM, Shapiro MF, Hays RD. Reliability and validity of self-report CD4 counts-in persons hospitalized with HIV disease. J Clin Epidemiol. 1997;50:829-35.

65. Brick JM, Kalton G. Handling missing data in survey research. Stat Methods Med Res. 1966;5:215-38. 
66. Duan N, McCaffrey DF, Frankel MR, et al. HCSUS Baseline Methods Technical Report. Santa Monica, Calif: RAND; 1999.

67. Kish L, Frankel MR. Inference from complex samples. J R Stat Soc B. 1974;36:1-37.

68. Wilson IB, Landon BE, Ding $\mathbf{L}$, et al. A national study of the relationship of care site HIV specialization to early adoption of highly active antiretroviral therapy. Med Care. 2005;43:12-20.

69. Essed P. Understanding Everyday Racism: An Interdisciplinary Theory. Newbury Park: Sage Publications; 1991.

70. Feagin JR, Sikes MP. Living With Racism: The Black Middle-Class Experience. Boston, Mass: Beacon Press; 1994.

71. Taylor DM, Wright SC, Porter LE. Dimensions of perceived discrimination: the personal/group discrimination discrepancy. In: Olson JM, ed. The Psychology of Prejudice: The Ontario Symposium, Vol 7. Hillsdale, NJ: Lawrence Erlbaum Associates Inc.; 1994:233-55.

72. Lee J, Gehlbach S, Hosmer DW, Reti M, Baker CS. Medicare treatment differences for blacks and whites. Med Care. 1997;35:1173-89.

73. Schneider EC, Cleary PD, Zaslavsky AM, Epstein AM. Racial disparity in influenza vaccination: does managed care narrow the gap between African Americans and whites? JAMA. 2001;286:1455-60.

74. Hooper EM, Comstock LM, Goodwin JM, Goodwin JS. Patient characteristics that influence physician behavior. Med Care. 1982;20:630-8.

75. van Ryn M, Fu SS. Paved with good intentions: do public health and human service providers contribute to racial/ethnic disparities in health? Am J Public Health. 2003;93:248-55.

76. Geiger HJ. Racial and ethnic disparities in diagnosis and treatment: a review of the evidence and a consideration of causes. In: Nelson AR, ed. Unequal Treatment: Confirming Racial and Ethnic Disparities in Health Care. Washington, DC: Institute of Medicine: 2002.

77. Marques JM, Yzerbyt VY, Leyens JP. The "Black Sheep Effects": extremity of judgments towards ingroup members as a function of group identification. Eur J Soc Psychol. 1988;18:1-16.
78. Marques JM, Abrams D, Serodio RG. Being better by being right: subjective group dynamics and derogation of in-group deviants when generic norms are undermined. J Pers Soc Psychol. 2001;81: 436-47.

79. Lerner MJ. The desire for justice and reactions to victims. In: Berkowitz L, ed. Altruism and Helping Behavior. New York, NY: Academic Press; 1970:205-29.

80. Kahn KL, Pearson ML, Harrison ER, et al. Health care for black and poor hospitalized Medicare patients. JAMA. 1994;271:1169-74.

81. Horsman JM, Sheeran P. Health care workers and HIV/AIDS: a critical review of the literature. Soc Sci Med. 1995;41:1535-67.

82. Passannante MR, French J, Louria DB. How much do health care providers know about AIDS? Am J Prev Med. 1993;9:6-14.

83. Kaplan SH, Greenfield S, Ware JE. Assessing the effects of physicianpatient interactions on the outcomes of chronic disease. Med Care. 1989;27(3, suppl):S110-27.

84. Thomson GE. Discrimination in health care. Ann Intern Med. 1997; 126:910-2.

85. Hadorn DC. The problem of discrimination in health care priority setting. JAMA. 1992;268:1454-9.

86. Gostin LO, Webber DW. HIV infection and AIDS in the public health and health care systems: the role of law and litigation. JAMA. 1998;279: 1108-13.

87. Richter D. Not in my office: medical professionals and their refusal to treat HIV/AIDS patients. Law Psychol Rev. 1999;23:179-93.

88. Gallop RM, Taerk G, Lancee WJ, Coates RA, Flanning M. A randomized trial of group interventions for hospital staff caring for persons with AIDS. AIDS Care. 1992;4:177-85.

89. Carroll JL. An exploration of AIDS education and teaching methods. AIDS Care. 1991;3:101-4.

90. Jemmott LS, Jemmott JB, Cruz-Collins M. Predicting AIDS patient care intentions among nursing students. Nurs Res. 1992;41:172-7.

\section{JOIN US!}

for the upcoming

MIDWEST SGIM Regional Meeting

September 30 - October 1

Hyatt Regency, Chicago

Meeting Theme:

General Internal Medicine - Preparing the Next Generation

Meeting highlights will include:

* Key note address on academic generalism by David Leach, ACGME Executive Director

* VA Research Symposium "Implementing Research into Practice"

* Two sessions for junior investigators on careers in health services or clinical research

* Workshops on fellowships and advance degree opportunities * Workshop on publishing vignettes by SGIM president-elect Bob Centor

More information available at: http://www.sgim.org/midwest.cfm 